\title{
Study on the Importance of the Layout Adjusting of Crop Farming Structure on Farmers' Income \\ -A Case Study of Xinjiang Wensu
}

Jiaojiao $\mathrm{Cao}^{1, \text { a }}$, Pengcheng Wang ${ }^{2, \mathrm{~b}}$

${ }^{1}$ College of Economics and Management, Tarim University, Alar, Xinjiang, 843300

${ }^{2}$ Economics and Management College, Tarim University, Alar, Xinjiang, 843300

a email, ${ }^{b}$ emai

Keywords: Xinjiang Wensu, Crop Farming, Structure and Layout

\begin{abstract}
Farming as a basis for agriculture, sustained and healthy development of farming is not only related to the development of agriculture, farmers are more related to real economic growth. In recent years the price of a variety of crops changing, largely peasant economy had an impact, in this case, we must be rational distribution of agricultural industry structure, the effective promotion of farmers' income. Xinjiang Wensu located in Aksu Prefecture, which mainly farming as the main source of income of farmers has very important significance on behalf of its layout optimization of crop structure. This review focuses on the current situation and structural layout planting Wensu analyzed, made several recommendations to optimize and to adjust the layout of the importance of farmers to increase crop structure for a summary.
\end{abstract}

\section{Introduction}

Wensu the population of the county economy in Xinjiang Aksu region, where most of the rural population, and therefore farmers' income has been the Wensu agriculture we need to explore the issue. As an important part of farming Wensu agriculture, the development of good Wensu farming is not only related to the rapid and stable development of agriculture Wensu, more related to real household income. In order to better the development of farming, we have to structure the layout of planting reasonably optimized to adjusting the structure of the layout of the farmers' income.

\section{Xinjiang Wensu Farming Situation and Problems}

Wensu located in the middle of the Tianshan Tuomuer south, the north Tarim Basin of Aksu Prefecture, part of Akzo area. Wensu geographically from north to south, the north is more mountainous southern and plains, structure and history accumulated geography makes Wensu formed a predominantly agricultural and animal husbandry, supplemented by agricultural and pastoral counties. Wensu has a library Ai grams river, Tuoshigan River, Blue River station, Kalayoule rolling river, wood Zhati River and other rivers, there are wood care Arz, Hainan and Taiwan orchids, 14 glaciers, these rivers and glaciers Wensu farming development and improvement of adequate water conditions. Wensu warm temperate continental arid climate, Xinjiang and other area hospitals larger temperature difference between day and night, the annual average temperature $10.10{ }^{\circ} \mathrm{C}$, average annual rainfall of 65.4 millimeters, the annual average frost-free period 185 days, which is the development of the fruit industry Wensu It provides excellent weather conditions. After years of development, now has developed into a Wensu cotton, rice and other staple crops are the main crops, fruit crops, diversified crop structure as a backup framework.

Although in recent years of continuous development and exploration, Wensu farming have made great progress, planting structure and layout of the industry becoming more and more reasonable, but compared with the development of farming in other regions, there are still a gap, especially now the price tends to decline steadily grown crops, specialty crops, fruit industry price volatility, international competitiveness is not strong enough, which to a large extent slowed Wensu planting of farmers' income growth effect. Argumentative, not only because of unstable market prices, but 
also because of crop structure is not perfect, the layout of planting structure did not reach the market with changes in demand and changes in a timely manner. Thus, farmers in planting crops, trees, fruit trees and so on is a certain blindness, hysteresis phenomenon, restricted Wensu farming economy, affecting farmers' income. Although in the past few years to resolve the long-standing farmers' slow increase objective status Wensu adopted a series of methods of crop structure layout exploration and research, such as plant varieties regional distribution, demonstration of new varieties, seed breeding field program and other measures, but the effect is still relatively small. Therefore, the structural optimization of the layout of farming is still Wensu urgent problem.

\section{The Xinjiang Wensu Layout Planting Structure Analysis}

In agriculture, an area in order to determine the advantages of growing crops, we tend to use comparative advantage, comparative advantage theory by the British political economist David Ricardo - proposed, which was used to guide agricultural production and regional specialization layout optimization which has a very important significance, concrete steps to its advantage crops analysis were as follows:

Step one: measure of comparative advantage model selection. Farming is a very dependent on natural resource industries, so the crop out of the use of the determination of comparative advantage is often affected by natural conditions, resource endowments, market and environmental factors, it is difficult to find a correlation with empirical research and practical calculation model of comparative advantage. In this paper, the crop measure model borrowed locational quotient constructed to reflect not only a natural condition, but also reflect the comparative advantage of crops model resource endowments, production scale, and other factors of interaction, the specific expression is:

$$
C_{i j}=\sqrt[n]{\prod_{\mathrm{k}=\mathrm{i}}^{\mathrm{n}}} X_{\mathrm{k}}^{a_{k}}
$$

( $C_{\mathrm{ij}}$ represents the production area $\mathrm{j}$ th comprehensive comparative advantage index of agricultural products, $X_{\mathrm{k}}$ represents the i region $\mathrm{j}$ th item $\mathrm{k}$ factor of agricultural products (such as resource endowments, production scale) comparative advantage index). When its judgment, if any one of the index tends to zero, the area tends to zero advantage indicators will also be lost; and if $C_{i j}>1$, j denotes the i-Zone has a certain kind of crops comprehensive comparison advantage; if

$C_{\mathrm{ij}}<1$, it indicates that the first crops $\mathrm{j}$ the $\mathrm{i}$ area does not have a comprehensive comparative advantage. The scale of production and natural resources of locational quotient of expression:

$$
X_{\mathrm{ij}}=\frac{Q_{i j} / \sum_{j} Q_{i j}}{\sum_{j} Q_{i j} / \sum_{i} \sum_{j} Q_{i j}}
$$

(Where $X_{\mathrm{ij}}$ is the i Zone j crop output efficiency (or the size of the index) location quotient; the $Q_{i j}$ j crop output efficiency (or scale) index of the i-th area since the locational quotient is the use of statistics to. the ratio represents the share of the crops grown its market competitiveness, so as to arrive crop of comparative advantage in the analysis of the ratio is that if all regions and output efficiency level (or scale index) index are different, then there is a region division of labor and comparative advantage.

Wensu cotton occupies a clear comparative advantage, crops in some areas has become a pillar industry, oil crops comparative advantage is not obvious. Food industry crop Wensu of advantageous industries, but the composite index, the comparative advantage Wensu food industry showed a downward trend, but the food industry is still the main pillar industries Wensu County. In recent years, oil Wensu acreage reduction, grain, cotton growing, and total yield per unit area has a lot of growth, indicating that centralized, large-scale level Wensu recent years cotton farming has certain advantages, grain, cotton cultivation in the stability of the structure has been a lot of 
adjustment, but the comparative advantage declined. And planting fruit such as apples, pears, dates and apricots has great comparative advantage, comparative advantage peaches showed a downward trend year by year, because the climate and geographical advantages Wensu as apples, pears, apricots and dates provides a unique growth advantage, bred these fruits very popular market, and the market for peaches Wensu demand is declining.

Adhere to the steady development of grain production Wensu than by eating food, special food, fodder grain, special food for a reasonable layout, focus on grain yields, reduce input costs of food production and ensure grain output steady. The specific objectives of food production can be divided into the following steps: First, to guide farmers to share the task of planting, to ensure long-term stable supply of food; Second, always adhere to food production as seed planting foundation planting status wavering; Third, strict implementation of food production responsibility system, strengthening food production supervision and assessment; Fourth, the implementation of food production benefiting the agriculture policy, to mobilize farmers to share planting tasks enthusiasm; Fifth, strengthen fine varieties promotion, increase food yield and quality. Sixth, increase the promotion of growth in technology to improve the efficiency of food production; Seventh, accelerate the development of food industry, promote the transformation of value-added food.

Wensu due to lack of light and heat conditions, the lower the efficiency of cotton, according to Diaojian area should gradually improve yields, increase assembly cotton acreage reduction policy, use some mature earlier, resistance and good yield good cotton varieties, focused on yield and quality improvement. Specific implementation steps can be divided into the following steps: First, to guide farmers to appropriate reduction of cotton acreage; Second, strengthen Wensu for the promotion of cotton varieties to improve yield and quality of cotton; Third, increase cotton growth promotion of technology to improve cotton production efficiency; Fourth, accelerate the industrial development of cotton, improve the conversion of cotton growth; Fifth, strengthen cotton quality management, guarantee the quality and the quality of cotton production.

Climatic and geographical conditions Wensu as apples, pears, dates and apricots and other fruits provides a unique production conditions, therefore, an appropriate increase in fruit cultivation area will Wensu has a very important practical significance, according to adjusted by area, choose fruit, technical support, to ensure the quality, speed up the transformation step gradual increase fruit acreage Wensu, which is divided into the following specific implementation steps: First, to guide farmers to change their ideas, gradual increase in fruit plantings ; Second, strengthen the cultivation of fruit for Wensu promotion, avoid blind planting farmers; Third, to provide free technical support for farmers fruit production, farmers avoid planting mistakes; Fourth, to strengthen the fruit products supervision and quality control to ensure satisfactory market produce fruit; Fifth, accelerate the industrial development of the fruit, promote the transformation of value-added fruit.

\section{The Importance of the Crop Structure Layout Adjustment in Wensu}

For farmers, the income must be reduced problem in agricultural structure, and dominated by farming households must be existence of this phenomenon unreasonable planting structure in. Based on current crop structure adjustment of the layout, more or less break the balance of the original planting structure, before the new plant structure is no perfect balance, uncoordinated situation is bound to arise, but with stable structure and layout of the new planting balance, in this process, we can gradually find out the planting structure and layout of the problems, to seize this issue effectively addressed, not only to meet the market demand for crops and, more importantly, can farmers reasonable layout, improve own income.

Planting Structure layout reasonable or not, in addition to considering whether the planting of local conditions, also have to take into account market demand, market demand related to the proceeds of the farmers, there is an inevitable trend revenue optimization, also will have higher earnings there are more optimized layout adjustment. Therefore, in order to meet the market demand, we must find not only meet the market demand and consistent structural layout Wensu actual planting. Thus, by adjusting the structure of the layout, it is bound to form a more rational 
structure and layout of planting direction at the same time to achieve the adjustment of industrial structure Wensu planting and sustainable development of agriculture, and effectively bring benefits to farmers increase.

To adjust planting structure and layout, not just to improve the income of farmers for some time, but should be sustained and stable increase farmers' income. Optimization of crop structure layout, structure and layout of the law to find out the feasibility and market price consistent, farmers can hope to earn more. In the layout of the crop structure adjustment, optimization of planting structure and layout to help improve the quality of planting Wensu efficiency and competitiveness, to protect the rigid requirements of farmers continued to increase, only to meet the growing material and cultural needs of farmers for the rapid and stable development of agriculture provides a solid human foundation.

\section{Conclusion}

In short, the layout of the crop structure adjustment, whether it is tuning structure, or reduce consumption, and also improving efficiency or, should meet market requirements, and the needs of the market or will lead to increase farmers income and promote farmers income. Therefore, we must apply sound scientific methods to identify the advantages of planting products, the implementation of the crop structure optimization, truly effective to improve the income of farmers.

\section{References}

[1] Wang Fangdan, Sun Wensheng. Optimizing Countermeasures in Hebei Province agricultural planting structure [J]. Jiangsu Agricultural Sciences, 2011, 01.

[2] Bing Qiao li. Way crop structure adjustment and an important role in the agricultural structure [J]. Science Communication, 2012 (04).

[3] Han Ji. Aksu Prefecture Planting Structure Adjustment Situation and Development Strategy [D]. Xinjiang Agricultural University, 2017.

[4] Wang Jing, Yang Baoren. Aksu Prefecture, Xinjiang Agricultural Industrialization dynamic comparative advantage analysis [J]. Northern Economy, 2010 (12).

[5] Li Hua. Thoughts and Suggestions on Aksu Agricultural Industrial Structure Adjustment [J]. Jiangsu Agricultural Science and Technology, 2004 (05).

[6] Wang Juan, Li Qing. Economic Investigation Villages. Southern minority areas in Xinjiang Wensu Case [J]. Modern Business Trade Industry, 2015 (01).

[7] Zhang Xin, Wang Gang, Liang Fei, Wang Guodong. Xinjiang Corps Liangmian sugar planting structure adjustment Situation and Development Strategy [J]. Journal of Anhui Agricultural Science and Technology, 2015 (18).

[8] Gao Wa, Tan Zhigang, Yan Shoulin. Wensu Ecological Agriculture to promote agricultural income [J]. Illustrated in Xinjiang, 2013 (09).

[9] Li Yulin, Sun Wensheng. Wensu Rice Industry and recommendations [J]. Rural Science and Technology, 2015 (10). 